\title{
Gender By Numbers: Is Your Education Course Dominated By Your Opposite Gender?
}

\author{
Sara Tranquada \\ FCT, M-ITI \\ Portugal \\ sara.tranquada@m-iti.org
}

\author{
Nuno Correia \\ NOVA Lincs, FCT \\ Portugal \\ nmc@fct.unl.pt
}

\author{
Ana Caraban \\ IST, M-ITI \\ Portugal \\ ana.caraban@m-iti.org
}

\begin{abstract}
In this paper we present Gender by Numbers, a physical and virtual prototype that exhibits the gender imbalances in the pursuit of future careers. Our system collects and measures relationships between courses and gender retrieved from university statistical data. Our goal is to explore how high school students can be nudged towards gender consciousness and be aware of the gender imbalance of a course before applying to the university.
\end{abstract}

Gender, Prototype, Physical, Virtual, Education, Equality, Bias

\section{INTRODUCTION}

"Boys are doctors. Girls are nurses. Boys are pilots. Girls are stewardesses." These are pages of a controversial book: "I'm Glad I'm a Boy! I'm Glad I'm a Girl!" created by Whitney Darrow, Jr. (a previous editorial cartoonist of The New Yorker magazine) that highlights the ridiculousness of gender norms. Published in 1970, the collection's stereotypes are still unfortunately relevant 48 years later (Lecher, 2018; Popova, 2014).

Statistics from the U.S.A. National Science Foundation about the percentage of women majors (i.e. Bachelor's, Master's, Doctoral), by field of degree (e.g. medical school, law school, physical science and computer science) demonstrate that from 1970 to 2010 women's participation in these fields increased. However, from 1985 onwards the percentage of women in computer science started to decrease (from almost $40 \%$ in 1985 to almost 20\% in 2010), while in the other fields it continued to increase to more than $40 \%$ by 2010 . This appears to be ongoing, as the field of computer science is dominated by men (Henn, 2014).

Patricia Ordóñez is a living example of that professional gender dynamic. Being herself a math wiz in school, she discovered that math could be applied to programing and to grasp computers. As a result, Computer Science became her interest. In her first introductory course at the John Hopkins University in the 1980s, she was faced with the bitter reality of having fewer than 6 female student colleagues in a class of 100 (Henn, 2014; Luna, 2016). Apparent this was one of the reason for eventually dropping out of the field.

To what point can a message persuade someone? Authors (Baesler and Burgoon, 1994) studied the understanding of message effects. They presented messages based on statistical evidence and others as narrative stories across multiple time periods (immediate, 48 hours later, or 1 week later). Although both proved persuasive compared to no evidence, statistical evidence was more persuasive than story, and when combined with vividness, it created more durable persuasion (1 week).

The convergence of physical and virtual worlds can link the "gap between theory and reality". (Wang and Tseng, 2018) explored which activities (physical, virtual or combined environmental) could better enhanced students' knowledge about evaporation and condensation. Activities in a combined environment were more efficient in helping students' conceptual understanding than either virtual or physical information alone, respectively.

Our aim in this preliminary study was to gently present to students the harsh reality of gender inequity in technical majors, in order not to demotivate them, but to inform them and prepare them through statistical messages. We will describe our research approach, and present a fresh design to enhance the most often encountered (virtual alone) statistical analysis for future college students by adding a haptic component. More specifically, this work aims to explore if a combined environment 
(virtual and physical) could have a critical impact on facilitating a clear observation of the uneven number of gender in the courses they apply to. We explore the benefits that both kinds of interactions can give us (physical - tactile interaction and virtual - visual animation) in order to optimize their interaction and impact.

\section{GENDER BY NUMBERS}

The design of Gender by Numbers was based on the missing elements of the website of the Portuguese Direção-Geral do Ensino Superior (DGES, a division of the Ministry of Science, Technology, and Education ("DGES," n.d.)). This site contains records of higher education applicants and placements in Portugal. The existing public site offers many statistics, however gender is tallied only for number of applicants as a total, and not by individual courses. The data used for this prototype is derived from that web site, focusing on preliminary on the applicant's choice only [Please note that the authors reuse the binary gender categories provided by government statistics; we address concerns with this reduction in the Future Work section].

Gender by Numbers uses a two-part selection (gender and course) interface, allowing a user to visualize and segment underlying statistics. We designed and developed a physical prototype (see Figure 1) as the centerpiece of the interaction with the web platform (see Figure 2).

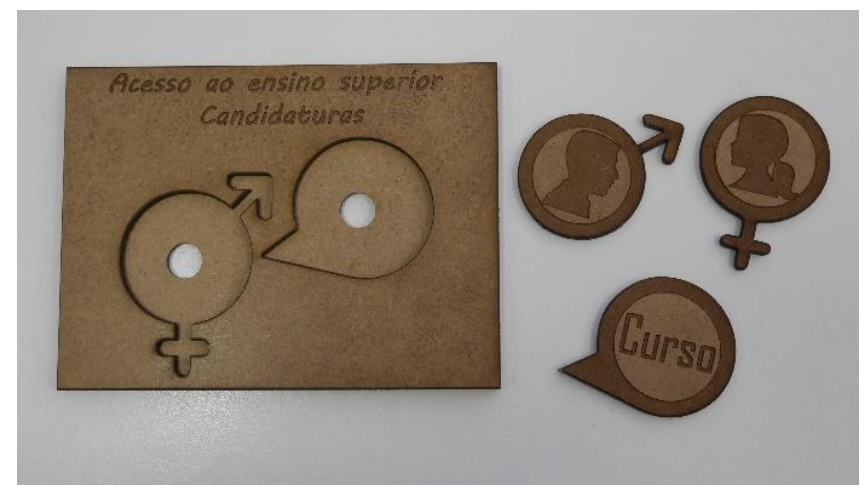

Figure 1: The physical part of the prototype - on the right a plaque title 'Access to higher education applications" and on the left: the pieces of a female and male accompanied with a piece representing the Courses.

\section{Nursing}

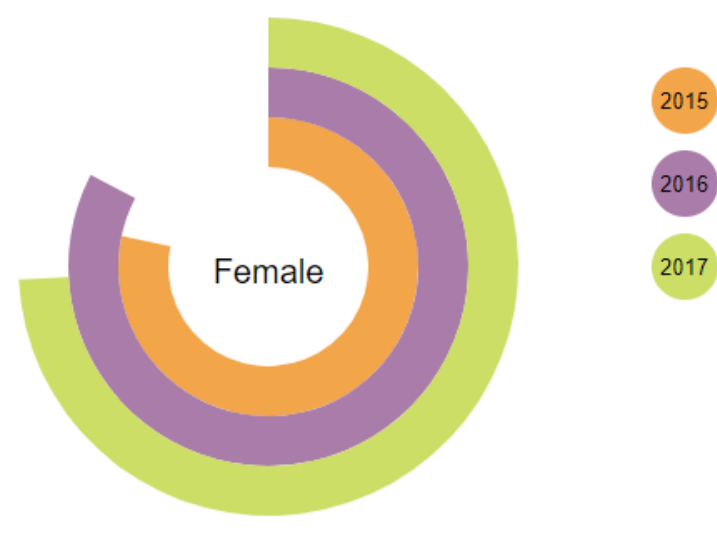

Figure 2: The virtual part of the prototype

Gender by Numbers first displays an animation with the percentage, represented by a pie chart, of the male students that applied to a course (e.g. Arts) within the last 3 years - viewed from inside to out (see Figure 3). Moments later the same animation occurs, changing its percentage this time to the female students (see Figure 4). This animation has a purpose to better demonstrate the contrast between applications by gender, be it increase, decrease or balance. The cycle repeats.

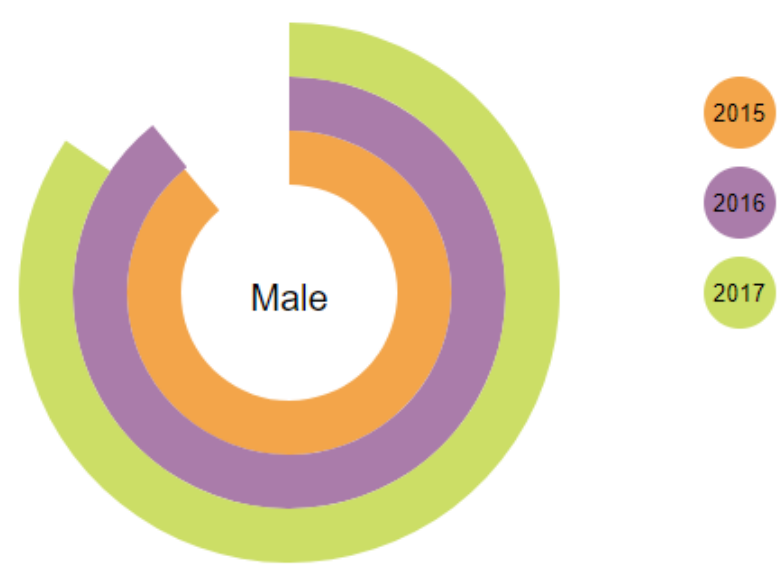

Figure 3: Male statistic of the Computer Science course. Male students started in 2015 with a majority, decreasing the percentage in 2017. 


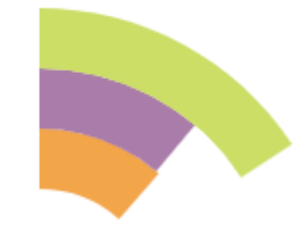

Female

Figure 4: Female statistics of the Computer Science course. In 2015 women were the minority, increasing the percentage in 2017.

Our physical prototype (see Figure 1), as mentioned before, serves to interact with the virtual prototype. For this purpose, the student needs to select the symbol that corresponds to his/her gender (i.e. female represented by an AIGA/airport female symbol inside of the female Linnaean symbol, and the corresponding male analogy) onto the base of the prototype (see Figure 1 - left side) and the intended course. The web application then displays statistical data of the course chosen (see Figure 3 and 4), and a text describing the percentage of his/her gender cohort if he/she applied to that course in the previous year (see Figure 5). The purpose of this selection was to better provide an understanding of the large discrepancy among courses by gender.

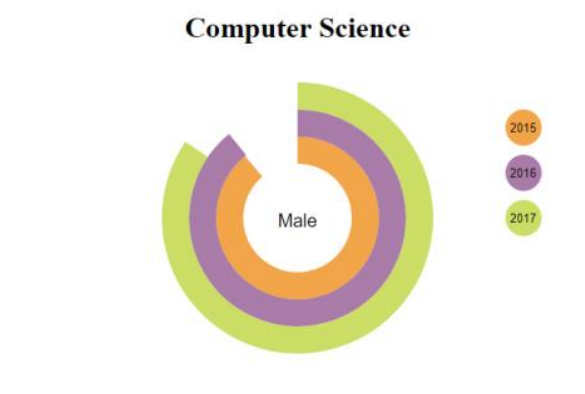

If you had applied last year into the program Computer Science,

you would have been a part of the $84 \%$ of the Male gender!

Figure 5: In this example, Computer Science and Male were chosen and this text would appear

\section{EXPERIMENTS}

We conducted a pilot experiment with 21 high school students ( 13 male and 8 female). The experiment was carried out during a visit to our university lab. Participation was completely voluntary (see Figure 6). During the visit, participants were asked the following questions: "Are you thinking of going to the university?" and "What courses are you considering applying to?" We gathered student's opinions using a "think aloud" protocol.

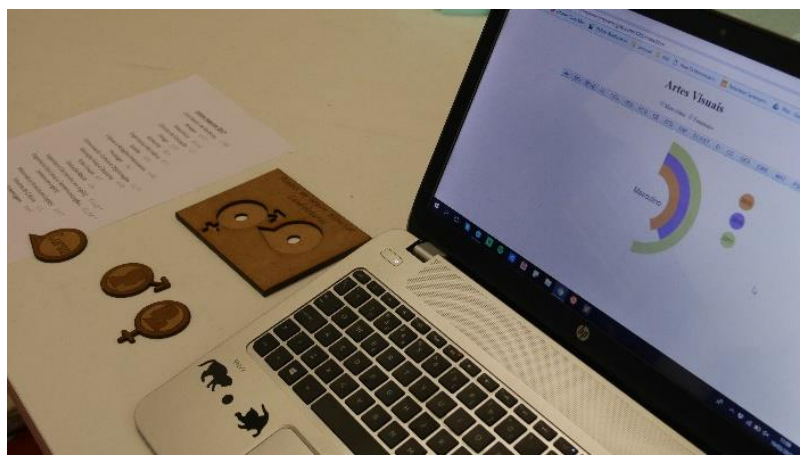

Figure 6 - The Scenario for the experiment.

Each participant underwent the same process (see Figure 7): students were asked to select their gender and a course, and then guess the perceived gender inequality (i.e. male or female majority). One researcher asked the participants to express their thoughts and recorded their reactions while interacting with the prototype. The physical prototype was not fully automatic yet; while the participants interacted with the pieces, the researcher inserted their selections (i.e. gender and course) into the virtual prototype (see Figure 7). Every interaction with the visual prototype was video recorded and their thoughts regarding the prototype were audio recorded. After the experiment, data recorded was transcribed and analysed.

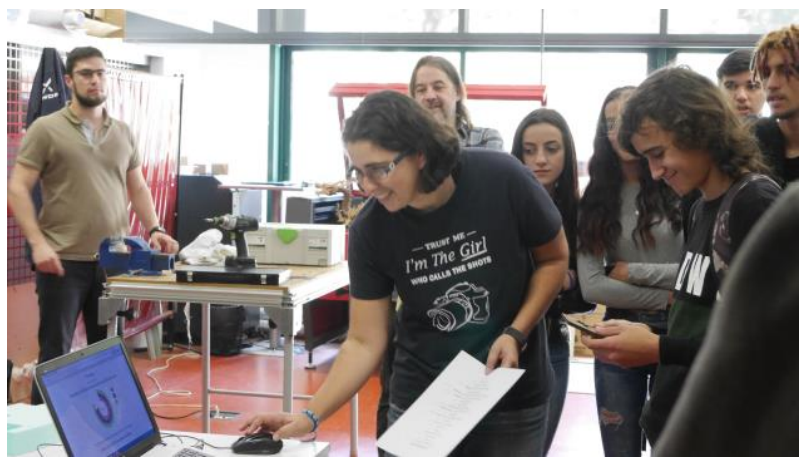

Figure 7: During the pilot test, a group of high school students were asked to interact with our system and observe gender distribution in different courses.

\section{DISCUSSION}

This research contributes with a web platform that displays a quantitative data of gender distribution across different courses. Our goal is to increase awareness of gender inequality in high school students before they apply to the university.

To increase engagement with the system, our prototype was devised as an interactive system that combines virtual and physical domains.

Our pilot test allowed us to observe that high school students were aware of some gender discrepancy (i.e. $62 \%$ of the students were correct on their guess as to who dominated the course). 
This consciousness increased throughout the experimentation. Further, we observed that the interaction between both prototypes (virtual and physical) was fluid and intuitive, and the information provided was understood.

Table 1: Some of the participant guesses and results (e.g. first Line: a male student wanted to see who dominates the Nursing Course, which he believes to be majority female students. Result: more female students than male, only $26 \%$ of students were Male in Nursing course)

\begin{tabular}{|l|l|l|l|}
\hline $\begin{array}{l}\text { Subject } \\
\text { Gender }\end{array}$ & Course & $\begin{array}{l}\text { Thought on } \\
\text { Domination }\end{array}$ & $\begin{array}{l}\text { Statistic } \\
\mathbf{2 0 1 7 / 2 0 1 8}\end{array}$ \\
\hline Male & Nursing & Female & $26 \%$ Male \\
\hline Female & $\begin{array}{l}\text { Physical education } \\
\text { and Sports }\end{array}$ & Male & $\begin{array}{l}37 \% \\
\text { Female }\end{array}$ \\
\hline Female & $\begin{array}{l}\text { Civil Engineering \& } \\
\text { Electronic }\end{array}$ & Male & $\begin{array}{l}20 \% \\
\text { Female }\end{array}$ \\
& Engineering and & & \\
& Telecommunications & & \\
\hline Male & Computer Science & Male & $84 \%$ Male \\
\hline Female & Basic Education & Female & $\begin{array}{l}88 \% \\
\text { Female }\end{array}$ \\
\hline Male & Culture Studies & Male & $36 \%$ Male \\
\hline Male & Medicine & Male & $20 \%$ Male \\
\hline Female & Psychology & Female & $83 \%$ \\
& & & Female \\
\hline
\end{tabular}

\section{CONCLUSION}

In this paper, we present the preliminary concept of Gender by Numbers, a system for exploring statistics to raise awareness of gender discrepancies among university courses. The underlying motivation was to raise awareness among future college students with the harsh reality, helping them to be conscious about the gender domination of a course before applying to the university. With this research, we want to draw attention to the gender bias surrounding technical field and non-technical fields.

\section{FUTURE WORK/ NEXT STEPS}

Our future work aims to improve "Gender by Number" by making the physical prototype fully interactive and able to retrieve more data from all the universities of the country.

Increasingly, gender is viewed in biology, sociology, and other fields as less of a binary and more of a spectrum or multi-dimensional network. The government statistics that this experiment was based on use a simple binary definition of gender, which constrained this initial work. This binary definition of gender may be problematic but nonetheless is still extremely determinant in society (Williams and Ceci, 2015), even while the implication of the binary varies considerably around the world (Nosek et al., 2009).

Work by (Tonso, 2006) and others have demonstrated how technical students have plural ranges of gender expression in technical fields, not necessarily in accordance with a binary gender category. The authors are aware that the binary interface presented in this prototype reinforces a simplistic binary of gender, and would like to explore alternatives, as this may open opportunities for more diverse technological possibilities.

\section{ACKNOWLEDGMENT}

This research was supported by ARDITI (Agência Regional para o Desenvolvimento da Investigação, Tecnologia e Inovação), Doctoral Grant under the Project M14-20 - 09-5369-FSE-000001.

\section{REFERENCES}

Baesler, E.J., Burgoon, J.K., 1994. The Temporal Effects of Story and Statistical Evidence on Belief Change. Commun. Res. 21, 582602. https://doi.org/10.1177/0093650940210050 02

DGES [WWW Document], n.d. URL http://www.dges.gov.pt/pt (accessed 1.26.17)

Henn, S., 2014. When Women Stopped Coding [WWW Document]. NPR.org. URL http://www.npr.org/sections/money/2014/10 /21/357629765/when-women-stoppedcoding (accessed 1.17.17).

Lecher, C., 2018. James Damore sues Google for allegedly discriminating against conservative white men [WWW Document]. The Verge. URL https://www.theverge.com/2018/1/8/16863 342/james-damore-google-lawsuitdiversity-memo (accessed 5.25.18).

Nosek, B.A., Smyth, F.L., Sriram, N., Lindner, N.M., Devos, T., Ayala, A., Bar-Anan, Y., Bergh, R., Cai, H., Gonsalkorale, K., Kesebir, S., Maliszewski, N., Neto, F., Olli, E., Park, J., Schnabel, K., Shiomura, K., Tulbure, B.T., Wiers, R.W., Somogyi, M., Akrami, N., Ekehammar, B., Vianello, M., Banaji, M.R., Greenwald, A.G., 2009. National differences in gender-science stereotypes predict national sex differences in science and math achievement. Proc. Natl. Acad. Sci. 106, 10593-10597. https://doi.org/10.1073/pnas.0809921106

Luna, R.I.M.D., 2016. Patricia Ordóñez: Propelling computer science into the health industry and equity [WWW Document]. Cienc. P. R. URL https://www.cienciapr.org/en/monthlystory/patricia-ordonez-propelling-computerscience-health-industry-and-equity (accessed 5.25.18).

Popova, maria, 2014. I'm Glad I'm a Boy! I'm Glad I'm a Girl! - Brain Pickings [WWW Document]. URL 
https://www.brainpickings.org/2014/01/20/i m-glad-im-a-boy-im-glad-im-a-girl-darrow/ (accessed 1.26.17).

Tonso, K.L., 2006. Student Engineers and Engineer Identity: Campus Engineer Identities as Figured World. Cult. Stud. Sci. Educ. 1, 273-307. https://doi.org/10.1007/s11422-005-9009-2

Wang, T.-L., Tseng, Y.-K., 2018. The Comparative Effectiveness of Physical, Virtual, and Virtual-Physical Manipulatives on Third-
Grade Students' Science Achievement and Conceptual Understanding of Evaporation and Condensation. Int. J. Sci. Math. Educ. 16, 203-219. https://doi.org/10.1007/s10763-016-9774-2

Williams, W.M., Ceci, S.J., 2015. National hiring experiments reveal 2:1 faculty preference for women on STEM tenure track. Proc. Natl. Acad. Sci. 112, 5360-5365. https://doi.org/10.1073/pnas.1418878112 